Tropical Journal of Pharmaceutical Research September 2021; 20 (9): 1783-1790

ISSN: $1596-5996$ (print); 1596-9827 (electronic)

(C) Pharmacotherapy Group, Faculty of Pharmacy, University of Benin, Benin City, 300001 Nigeria.

\title{
Optimization of Clostridium tyrobutyricum encapsulation by extrusion method and characterization of the formulation
}

\author{
Muhammad Umar Yaqoob1, Bin Wang ${ }^{2}$, Xun Pei ${ }^{1}$, Zhiping Xiao1, Wanjing Sun ${ }^{1}$, \\ Yuyue Jin', Lujie Liu ${ }^{1}$, Wenjing Tao ${ }^{1}$, Geng Wang ${ }^{1}$, Haidong Wang ${ }^{1}$, Minqi \\ Wang $^{1 *}$ \\ ${ }^{1}$ College of Animal Science, Zhejiang University, Key Laboratory of Animal Nutrition and Feed Science (Eastern China), \\ Ministry of Agriculture, Hangzhou 310058, ${ }^{2}$ Shanghai Zoo, 2381 Hongqiao Rd, Shanghai 200335, PR China
}

*For correspondence: Email: wangmq@zju.edu.cn; Tel: +86 571 88982112; Fax: +86 57188982650

\begin{abstract}
Purpose: To optimize the process parameters for the encapsulation of Clostridium tyrobutyricum (Ct) and to determine its in vitro characteristics.

Methods: The process parameters, including the concentration of the wall and hardening material, Ct to gelatin ratio and hardening time, were studied by single factor analysis, while optimization was performed by orthogonal experimental design for the encapsulation rate of $\mathrm{Ct}$.

Results: Optimal conditions exhibited by orthogonal experimental design at a $92.17 \%$ encapsulation rate with a viable count of $9.61 \pm 0.06 \mathrm{lgCFU} / \mathrm{g}$ were: $6 \%$ modified starch, $3 \%$ sodium alginate, and 2 $\% \mathrm{CaCl}_{2}$ at a $\mathrm{Ct}$ to gelatin ratio of 1:1 with a hardening time of $30 \mathrm{~min}$. The survival rates of encapsulated Ct were higher than free Ct in simulated gastric (6.22\%) and intestinal juices (15.55 \%). Reduction in viable counts of $\mathrm{Ct}$ at $90{ }^{\circ} \mathrm{C}$ were higher for free cells (44.76\%) than encapsulated cells (28.09\%) after 30 min of heat treatment. Correspondingly, encapsulation boosted the capacity of $\mathrm{Ct}$ to withstand the strong acidic conditions of the stomach and improved the storage properties of Ct.

Conclusion: The results suggested that extrusion is a good technique for the encapsulation of Ct, as it enhances the viability of $\mathrm{Ct}$ during their transit through the gastrointestinal tract. Furthermore, encapsulation is favorable for Ct if planned for use in formulations where high temperature treatment is required.
\end{abstract}

Keywords: Encapsulation, Acid resistance, Bile salt tolerance, Clostridium tyrobutyricum, Extrusion, In vitro simulation, Temperature tolerance

This is an Open Access article that uses a funding model which does not charge readers or their institutions for access and distributed under the terms of the Creative Commons Attribution License (http://creativecommons.org/licenses/by/4.0) and the Budapest Open Access Initiative (http://www.budapestopenaccessinitiative.org/read), which permit unrestricted use, distribution, and reproduction in any medium, provided the original work is properly credited.

Tropical Journal of Pharmaceutical Research is indexed by Science Citation Index (SciSearch), Scopus, International Pharmaceutical Abstract, Chemical Abstracts, Embase, Index Copernicus, EBSCO, African Index Medicus, JournalSeek, Journal Citation Reports/Science Edition, Directory of Open Access Journals (DOAJ), African Journal Online, Bioline International, Open-J-Gate and Pharmacy Abstracts

\section{INTRODUCTION}

Probiotics are live microorganisms that have beneficial effects on the host when fed in adequate amounts. Although probiotics have many physiological functions, such as killing harmful bacteria, improving digestion and absorption, and enhancing growth, productivity and intestinal immune function [1], there are many problems associated with their application as feed additives. These include low survival of live bacteria during processing and 
transportation; difficulty withstanding low $\mathrm{pH}$ in the stomach; and difficulty in resisting adverse environmental conditions during feed processing, such as heating, pelleting and storage. Therefore, it is an interesting topic of research for nutritionists to resolve these challenging situations.

Microencapsulation (ME) is an important technology that not only improves the resistance of probiotics to adverse environments but also safely transfers them to the target site in the intestine to play a specific role. In recent years, reports on probiotic $\mathrm{ME}$ enhancing the survival rate of Lactobacillus up to $10^{6} \mathrm{CFU} / \mathrm{mL}$ in simulated gastric fluid have been published [2]. Encapsulation of lactic acid bacteria using calcium alginate as a wall material significantly improves heat resistance and gastrointestinal survival [3]. Annan et al [4] found a significantly higher survival rate of Bifidobacteria in encapsulated form than as free bacteria (FB) in simulated gastrointestinal fluids.

Extrusion is a simple technique used for ME of different materials. Bajracharya et al [5] observed a $99 \%$ encapsulation rate of pig-derived lactic acid using sodium alginate (Na-alginate; $2 \%$ ) with $\mathrm{CaCl}_{2}$ solution $(0.1 \mathrm{~mol} / \mathrm{L})$ as the hardening fluid at $45{ }^{\circ} \mathrm{C}$ through the extrusion method with $70 \%$ more bioavailability under simulated gastric fluid $(\mathrm{pH} 2)$ than in the unprotected form. In most ME techniques, alginate is used as a wall material due to its nontoxic nature and acceptance as a food additive. However, huge variation in the dose rate of $\mathrm{Na}$ alginate is quoted in the literature [6-8]. A similar situation was reported in the case of $\mathrm{CaCl}_{2}$ concentration and hardening time of the capsules [9-11]. Although encapsulation significantly improves the survival of probiotics in different situations, huge variation in the concentration and type of wall materials and lack of consideration of all parameters make it difficult to select the best parameters.

This study was designed to optimize the process parameters for microencapsulation of $\mathrm{Ct}$ at maximum rate with more viable bacteria and in vitro characterization of prepared microcapsules under different conditions.

\section{EXPERIMENTAL}

\section{Bacteria, growth medium and preparation of cell suspension}

Clostridium tyrobutyricum (Ct) ATCC25755 was grown on clostridial growth medium (CGM) at 37 ${ }^{\circ} \mathrm{C}$ under anaerobic conditions and propagated through fermentation at $37^{\circ} \mathrm{C}$ with continuous stirring at $150 \mathrm{rpm}$ and $6.0 \mathrm{pH}$. A bacterial growth curve was developed by measuring the absorbance $(600 \mathrm{~nm})$ every $6 \mathrm{~h}$. The composition of CGM was the same as that used previously [9]. The cell suspensions obtained through fermentation were used either directly (free cells) in analysis or for ME.

\section{Microencapsulation and optimization}

The cell suspension $\left(6.5 \times 10^{9} \mathrm{CFU} / \mathrm{g}\right)$, modified starch (M-starch) and sterilized $\mathrm{Na}$-alginate solution were mixed evenly and extruded into $\mathrm{CaCl}_{2}$ solution to produce microencapsulated bacteria (MEB) and solidified at room temperature. The viable count was determined by a previous method [10], and the microencapsulation rate (ME rate) was calculated as in Eq. 1.

$\mathrm{ME}$ rate $=\mathrm{C} 1 / \mathrm{C} 2 \times 100$

where $\mathrm{C} 1$ is the viable count (CFU/g) in microcapsules and $\mathrm{C} 2$ is the viable count (CFU/mL) of FB.

All process parameters (Table 1) were studied by single factor analysis ANOVA to determine the effects of individual parameters on the ME rate. An orthogonal experimental design was used to obtain the best combination of all factors to achieve an optimal ME rate $[27,28]$.

\section{In vitro characterization of microencapsu- lated $\mathrm{Ct}$}

Encapsulated bacteria were evaluated by a twostage in vitro assay. Gastrointestinal simulated solutions were prepared following the method of Yaqoob et al. [9], and simulation was performed according to the procedure of Etchepare et al [11].

Table 1: Factors studied in singe factor and orthogonal experimental design

\begin{tabular}{ccccc}
\hline Na-alginate (w/v) & M-starch $(\mathbf{w} / \mathbf{v})$ & $\mathbf{C a C l}_{\mathbf{2}}(\mathbf{w} / \mathbf{v})$ & $\mathbf{C t . :}$ gelatin (v:v) & Hardening time (min) \\
\hline 1 & 4 & 1 & $1: 01$ & 10 \\
2 & 5 & 2 & $1: 02$ & 20 \\
3 & 6 & 3 & $1: 03$ & 30 \\
4 & 7 & 4 & $1: 04$ & 40 \\
\hline
\end{tabular}


Bile salt resistance was evaluated by treating MEB or FB (1 $\mathrm{g}$ or $1 \mathrm{ml}$ ) with bile liquid $(9 \mathrm{ml}$ of $0.3 \%$ pig bile salt solution) at $37^{\circ} \mathrm{C}$ for $3 \mathrm{~h}$ with constant agitation (50 rpm) [12].

MEB and FB were treated with hot water at 60 or $90{ }^{\circ} \mathrm{C}$, and changes in the number of live bacteria were counted at different intervals of time to examine their resistance to changes in temperature [3]. Acid resistance and storage kinetics were studied by following the methods of Ding and Shah [13] and Etchepare et al [11], respectively. All in vitro analysis were run in triplicates.

\section{Statistical analysis}

Data regarding the effects of individual factors on the $\mathrm{ME}$ rate and in vitro characteristics were analyzed by one-way ANOVA in SPSS 20.0 and expressed as the mean \pm SD. To determine statistically significant differences among treatments, Tukey's test was used $(p<0.05)$.

\section{RESULTS}

\section{Bacterial growth curve}

Figure 1 shows that $0-12 \mathrm{~h}$ was the adaptation period followed by the growth phase $(12-24 \mathrm{~h}$ ) of $\mathrm{Ct}$, while the growth curve at $24-36 \mathrm{~h}$ indicated that the total number of bacteria was no longer growing, and the viability of the entire flora gradually decreased, which might be due to the depletion of nutrients, accumulation of toxic products and decline in $\mathrm{pH}$.

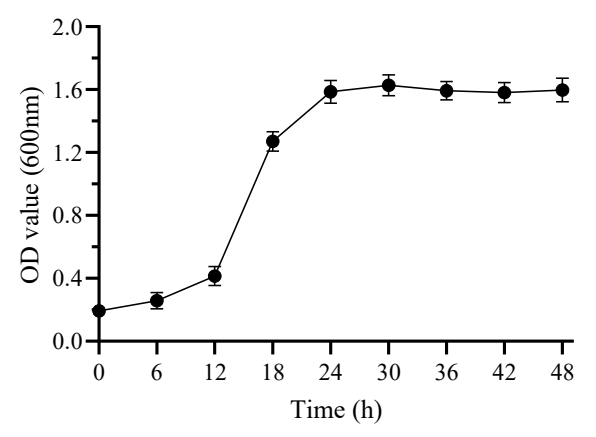

Figure 1: Bacterial growth curve

\section{Optimized microencapsulation process}

The ME rate under different experimental conditions is shown in Figure 2 a-e. The maximum ME rate $(77.31 \%)$ with the highest number of live bacteria $\left(3.8 \times 10^{9} \mathrm{CFU} / \mathrm{g}\right)$ was obtained by hardening the microcapsules for 30 min (Figure 2 a). A further increase in hardening decreased the $\mathrm{ME}$ rate $(10.09 \%)$ and viable counts $(15.79 \%)$. Figure $2 \mathrm{~b}$ shows that the ME rate was increased by increasing the concentration of M-starch, and the maximum ME rate $(89.60 \%)$ was obtained by using $7 \% \mathrm{M}$ starch. When the concentration of $\mathrm{Na}$-alginate was less than or equal to $3 \%$, a positive relationship was observed between the $\mathrm{Na}$ alginate concentration and $\mathrm{ME}$ rate, reaching a maximum rate of $87.98 \%$ at a concentration of 3 $\%$, but a further increase in the concentration of $\mathrm{Na}$-alginate negatively affected the yield of the product (Figure $2 \mathrm{c}$ ). Similarly, the ME rate was also increased by increasing the $\mathrm{CaCl}_{2}$ concentration up to $2 \%$ (Figure $2 \mathrm{~d}$ ). The highest ME rate $(78.44 \%)$ was obtained by using $2 \%$ $\mathrm{CaCl}_{2}$ solution, and a further increase in its concentration decreased the ME rate. At $4 \%$ $\mathrm{CaCl}_{2}$, a $14.63 \%$ reduction in the $\mathrm{ME}$ rate was observed. Single factor analysis of the $C t$ to gelatin ratio showed that $1: 3$ was the best ratio for the peak $\mathrm{ME}$ rate $(78.28 \%)$ under the conditions of this study (Figure 2 e).
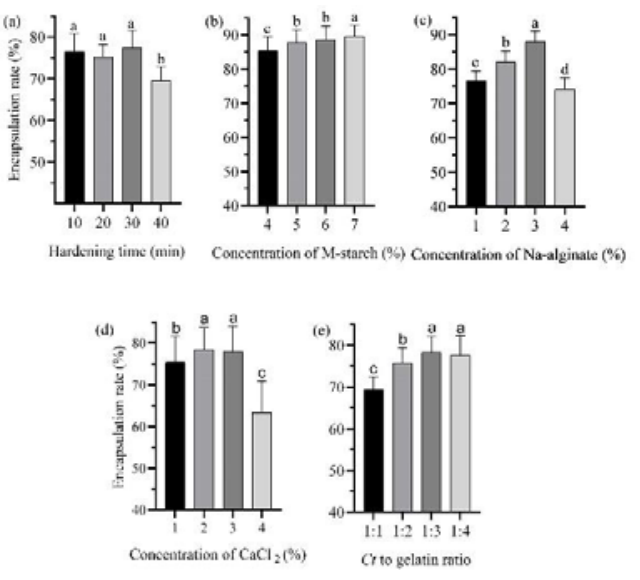

Figure 2: (a) Effect of hardening time, (b) concentration of modified starch, (c) concentration of sodium alginate, (d) concentration of calcium chloride, (e) proportion of $\mathrm{Ct}$ and wall material on microencapsulation rate of $\mathrm{Ct}$. All data were presented as mean $\pm S D, n=6$. Different letters on the top of bars shows statistical difference $(p<0.05)$

According to the results of the orthogonal design test, the order of four key factors affecting the $\mathrm{ME}$ rate was Na-alginate concentration $>\mathrm{Ct}$ to gelatin ratio $>\mathrm{CaCl}_{2}$ concentration $>\mathrm{M}$-starch concentration. The best combination of parameters was $6 \% \mathrm{M}$-starch, $3 \% \mathrm{Na}$-alginate, $2 \% \mathrm{CaCl}_{2}$, and $\mathrm{Ct}$ to gelatin ratio of $1: 1$ with a hardening time of $30 \mathrm{~min}$, which were validated by a follow-up experiment, and the highest ME rate $(92.17 \%)$ and viable counts $(9.61 \pm 0.06$ $\mathrm{LgCFU/g)} \mathrm{were} \mathrm{observed} \mathrm{at} \mathrm{these} \mathrm{selected}$ parameters compared to 16 combinations studied previously (Table 2). 
Table 2: The orthogonal design and ME rate of $C t$. at four levels of four different factors

\begin{tabular}{|c|c|c|c|c|c|}
\hline \multirow[b]{2}{*}{ No. } & \multicolumn{4}{|c|}{ Factors } & \multirow[b]{2}{*}{ ME rate $(\%)$} \\
\hline & Na-alginate (w/v) & M-starch (w/v) & $\mathrm{CaCl}_{2}(\mathrm{w} / \mathrm{v})$ & $\begin{array}{c}\text { Ct.: gelatin } \\
\text { (v:v) }\end{array}$ & \\
\hline 1 & 1 & 4 & 1 & $1: 1$ & 67.2 \\
\hline 2 & 1 & 5 & 2 & $1: 2$ & 72.6 \\
\hline 3 & 1 & 6 & 3 & $1: 3$ & 75.4 \\
\hline 4 & 1 & 7 & 4 & $1: 4$ & 69.5 \\
\hline 5 & 2 & 4 & 2 & $1: 3$ & 82.3 \\
\hline 6 & 2 & 5 & 1 & $1: 4$ & 74.6 \\
\hline 7 & 2 & 6 & 4 & $1: 1$ & 90.7 \\
\hline 8 & 2 & 7 & 3 & $1: 2$ & 66.8 \\
\hline 9 & 3 & 4 & 3 & $1: 4$ & 78.3 \\
\hline 10 & 3 & 5 & 4 & $1: 3$ & 83.9 \\
\hline 11 & 3 & 6 & 1 & $1: 2$ & 78.1 \\
\hline 12 & 3 & 7 & 2 & $1: 1$ & 88.7 \\
\hline 13 & 4 & 4 & 4 & $1: 2$ & 68.4 \\
\hline 14 & 4 & 5 & 3 & $1: 1$ & 75.5 \\
\hline 15 & 4 & 6 & 2 & $1: 4$ & 81.3 \\
\hline 16 & 4 & 7 & 1 & $1: 3$ & 74.6 \\
\hline \multicolumn{6}{|l|}{ Value } \\
\hline k1 & 71.18 & 74.05 & 73.63 & 80.53 & \\
\hline k2 & 78.60 & 76.65 & 81.23 & 71.48 & \\
\hline k3 & 82.25 & 81.38 & 74.00 & 79.05 & \\
\hline k4 & 74.95 & 74.90 & 78.13 & 75.93 & \\
\hline $\mathrm{R}$ & 11.08 & 7.32 & 7.60 & 9.05 & \\
\hline
\end{tabular}

Note: k1-k4 values are average rate of ME for each factor at levels 1-4, respectively; $R$ is the range for each factor. A larger $\mathrm{R}$ value indicates a greater effect of the factor on the process

\section{In vitro gastrointestinal simulation}

The results showed that $\mathrm{ME}$ protected the bacteria from the strongly acidic and basic conditions of the stomach and intestine, respectively. The survival rates of MEB and FB at $\mathrm{pH} 1.2$ were 96.25 and $90.03 \%$, respectively, after $2 \mathrm{~h}$ of contact time. After simulated gastric solution, bacteria were placed in simulated intestinal solution ( $\mathrm{pH} 7.4)$, and after $4 \mathrm{~h}$ Of treatment, their survival rates were 85.80 and $70.25 \%$ for MEB and FB, respectively (Figure 3 ).

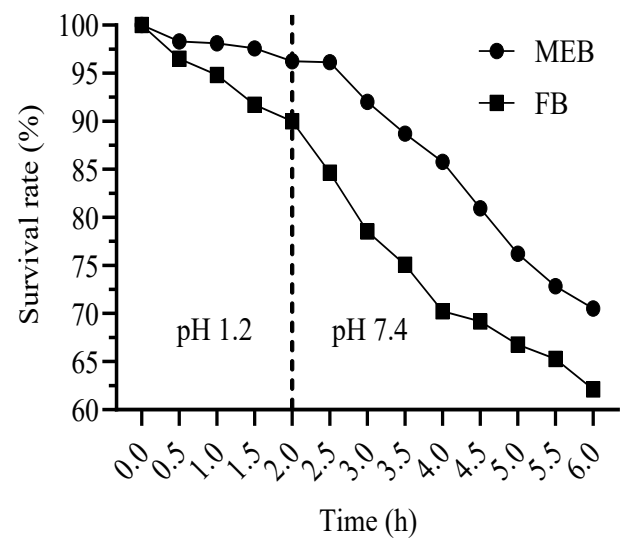

Figure 3: In vitro characteristics of MEB vs. FB. Effect of simulated gastric and intestinal fluid. All data were presented as mean $\pm S D, n=6$

\section{Acid tolerance}

Results show that $C t$ was less resistant to a strongly acidic environment, and ME improved its tolerance because at low $\mathrm{pH}(1-4)$, the survival rate of MEB was higher than that of FB (Figure 4 ). After $4 \mathrm{~h}$ of acid treatment, the decrease in the number of live MEB was $1.05 \mathrm{LgCFU} / \mathrm{g}$, whereas FB decreased by $1.99 \mathrm{LgCFU} / \mathrm{mL}$.

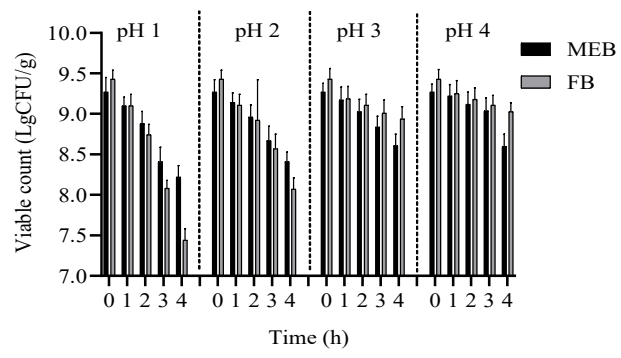

Figure 4: Acid tolerance of MEB vs. FB. All data were presented as mean $\pm S D, n=6$

\section{Temperature tolerance}

The effect of temperature treatment showed that ME significantly improved the resistance ability of $\mathrm{Ct}$ against high temperature $\left(90^{\circ} \mathrm{C}\right)$ (Figure 5). The reduction in the viable count of MEB after 15 and $30 \mathrm{~min}$ of treatment at $90{ }^{\circ} \mathrm{C}$ was 8.74 and $28.09 \%$, respectively, while that of FB was 27.41 and $44.76 \%$, respectively. 


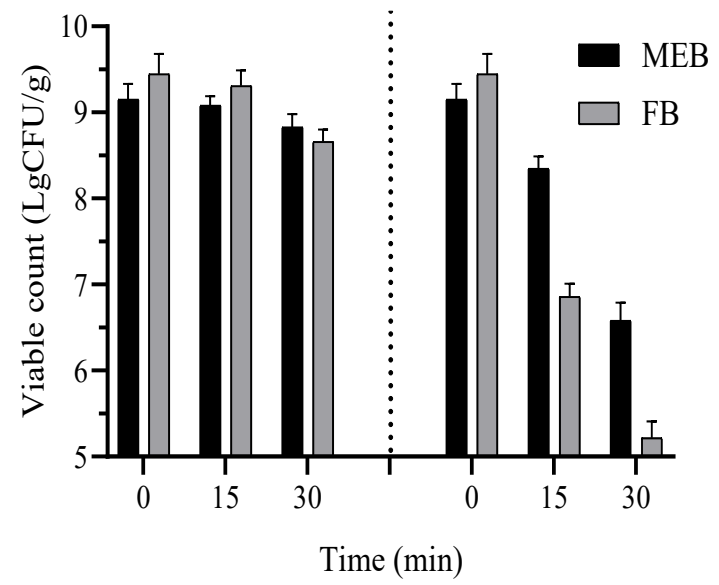

Figure 5: Effect of heat treatment on MEB vs. FB. All data were presented as mean $\pm S D, n=6$

\section{Bile salt tolerance}

The results of the $0.3 \%$ bile salt treatment revealed that $\mathrm{ME}$ had no effect against bile salt tolerance (Figure 6). The survival of MEB after 1 , 2 and $3 \mathrm{~h}$ of bile salt treatment was $99.60,98.13$ and $96.95 \%$, respectively, of the initial count, while that of FB was $99.15,97.50$ and $96.86 \%$, respectively, under the same conditions.

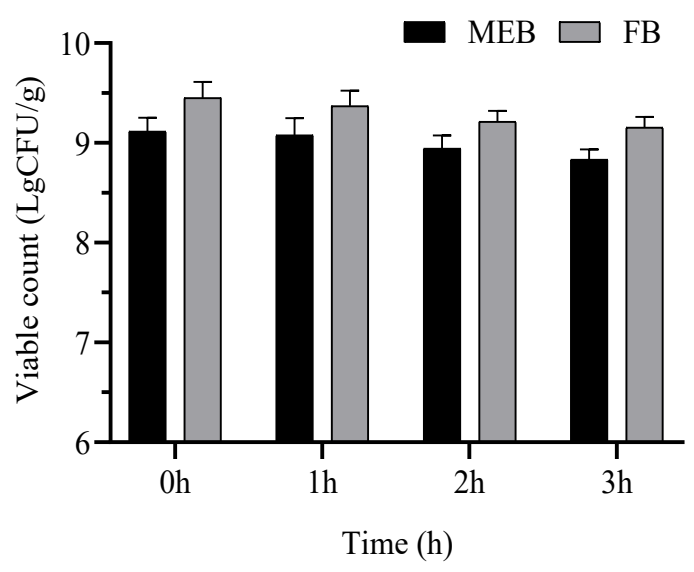

Figure 6: Comparative survival of MEB vs. FB in bile salt solution. All data were presented as mean $\pm S D, n$ $=6$

\section{Storage kinetics}

Storage kinetics of $\mathrm{Ct}$ in microencapsulated or free form are presented in Figure 7. The initial concentrations of MEB and FB were $9.11 \pm 0.29$ $\mathrm{LgCFU} / \mathrm{g}$ and $9.23 \pm 0.14 \mathrm{LgCFU} / \mathrm{mL}$, respectively. Samples were stored at $25^{\circ} \mathrm{C}$, and the total reduction in viable count was lower in MEB (1.56 LgCFU/g) than FB (2.07 LgCFU/mL), meaning ME enhanced the shelf life of $C t$.

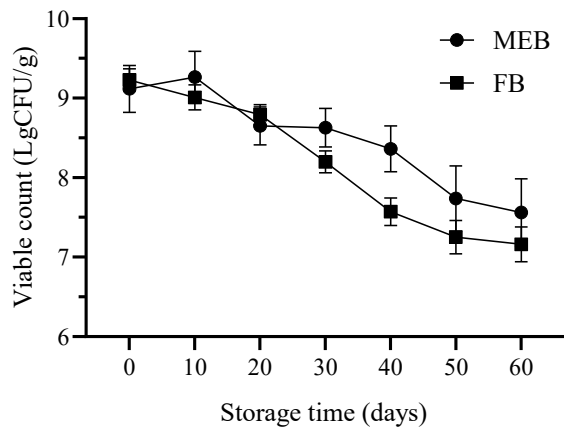

Figure 7: Storage kinetics of MEB vs. FB at $25^{\circ} \mathrm{C}$ for storage time of 60 days. All data were presented as mean $\pm \mathrm{SD}, \mathrm{n}=6$

\section{DISCUSSION}

The results showed that 30 min was sufficient for hardening of microcapsules, as cited previously [2]. A shorter hardening time might be inadequate for the complete reaction between Na-alginate and $\mathrm{CaCl}_{2}$; on the other hand, prolonged hardening might be the reason for the entry of some calcium ions into the microcapsule. The use of M-starch was in line with Sultana et al [7], and the maximum ME rate was obtained by using $3 \%$ Na-alginate. A possible reason might be the formation of a thinner capsule wall at lower concentrations of Na-alginate. When the bacteria to gelatin ratio was less than $1: 3$, the encapsulation rate increased with an increasing ratio. At a higher proportion of gelatin to bacteria, more wall material resulted in thicker capsules, which enhanced the protection of bacteria and the rate of encapsulation.

In the present study, a positive relationship was found among the ME rate, viability count and concentration of $\mathrm{CaCl}_{2}$ used up to $2 \%$; a further increase in its concentration negatively affected the $\mathrm{ME}$ rate. This might be due to the limited number of calcium ions bound with $\mathrm{Na}$-alginate. Similarly, Mandal et al [14] suggested that the use of Na-alginate in the ME of Lactobacillus casei and hardening of its capsules in $0.1 \mathrm{M}$ $\mathrm{CaCl}_{2}$ significantly improved its survival at low $\mathrm{pH}$ and high bile salt concentration when compared to FB. In this study, the combination of M-starch and Na-alginate to form a composite wall effectively protected the bacteria and improved their encapsulation efficiency compared with a single wall of $\mathrm{Na}$-alginate.

The survival rate of FB after $2 \mathrm{~h}$ in the simulated stomach fluid was $90.03 \%$ and that of MEB was $96.25 \%$, which indicated that ME improves the survival of Ct. Correspondingly, lyer and Kailasapathy [15] suggested that the use of Himaize starch, chitosan and alginate to 
encapsulate Lactobacillus acidophilus increased its resistance to the GIT environment. Similarly, Bifidobacteria [14,16-18] and Lactobacilli $[6,19]$ showed higher viability with alginate encapsulation when incubated in simulated gastric fluid. Results of the present study showed that $C t$ is less resistant to strong acids, and encapsulation improved its tolerance, as suggested by previous studies [20,21]. This was due to the barrier effect of the microcapsule wall on acid, which prevents it seeping into the microcapsule. Previous studies on Lactobacillus casei [14] and Lactobacillus acidophilus [2] also support the results in this study. In addition, the M-starch added to the wall has a strong adsorption effect and indirectly enhances the tolerance of the internal $\mathrm{Ct}$ to the acidic environment. However, contrasting results have also been reported in the literature, showing that alginate $\mathrm{ME}$ does not effectively protect microorganisms at low $\mathrm{pH}[7,20,22]$.

According to the results of the present study, ME has no protective effect against bile salt treatment, as reported by Yaqoob et al [9]. Similarly, higher mortality of encapsulated Bifidobacteria [16], Bifidobacterium bifidum and Lactobacillus acidophilus [19] was seen after bile salt treatment. Contradictory findings have been reported in the literature, in which encapsulation could significantly enhance probiotic resistance to bile salts $[2,17]$. The inconsistency could be attributed to the use of different encapsulation parameters, methods and types or strains of probiotics.

Encapsulation enhanced the tolerance of bacteria against high temperatures of 65 and 90 ${ }^{\circ} \mathrm{C}$, as reported by Ding and Shah [13] and Yaqoob et al [9], respectively. This is similar to the results obtained in this study. The present results are also supported by the study of Mandal et al [14], which reported that high-temperature treatment drastically reduced the viable counts of Lactobacillus in free form and that alginate encapsulation increased its viability under such conditions. Higher survival of encapsulated $\mathrm{Ct}$ might be due to slower diffusion of water in the capsule at high temperature.

The storage kinetics results are in line with previous findings $[6,23]$. In another study, viable FBs were observed after storage at room temperature for 7 days, but little change in counts was observed by encapsulation of the same bacteria for up to 14 days [24]. The increase in survival rate might be due to reduced moisture contents in encapsulated form because probiotics survive longer in a dried environment than under liquid conditions [25,26].

\section{CONCLUSION}

The findings of this study indicate that the best process parameters/conditions for encapsulation of $\mathrm{Ct}$ by the extrusion method are $6 \% \mathrm{M}$ starch and $3 \% \mathrm{Na}$-alginate at a $\mathrm{Ct}$ to gelatin ratio of $1: 1$ $(\mathrm{v} / \mathrm{v})$ with a $30 \mathrm{~min}$ hardening time in $2 \% \mathrm{CaCl}_{2}$ solution. Encapsulated $\mathrm{Ct}$ produced under these conditions survive better in simulated GIT conditions with higher resistance to harsh environmental conditions and comparatively longer shelf life than free Ct.

\section{DECLARATIONS}

\section{Acknowledgement}

The authors are thankful for financial support from The National Key Research and Development Program of China (no. 2018YFE0112700) and The Science and Technology Key Project of Zhejiang Province, China (no. 2019C02005) for this study.

\section{Conflicts of interest}

No conflict of interest is associated with this work.

\section{Contribution of authors}

We declare that this work was done by the authors named in this article, and all liabilities pertaining to claims relating to the content of this article will be borne by the authors. Minqi Wang designed the study, Junbiao Zou and Dongbi Leng conducted the extrusion experiment, Bin Wang, Xun Pei and Muhammad Umar Yaqoob performed the in vitro analysis, while Zhiping Xiao, Wanjing Sun, Yuyue Jin, Lujie Liu, Wenjing Tao, Geng Wang and Haidong Wang analyzed and interpreted the data. Muhammad Umar Yaqoob prepared the manuscript, and Minqi Wang critically reviewed the manuscript, which was then approved by all authors.

\section{Open Access}

This is an Open Access article that uses a funding model which does not charge readers or their institutions for access and distributed under the terms of the Creative Commons Attribution License (http://creativecommons.org/licenses/by/ 4.0) and the Budapest Open Access Initiative (http://www.budapestopenaccessinitiative.org/rea d), which permit unrestricted use, distribution, and reproduction in any medium, provided the original work is properly credited.

Trop J Pharm Res, September 2021; 20(9): 1788 


\section{REFERENCES}

1. Alagawany M, Abd El-Hack ME, Farag MR, Sachan S, Karthik K, Dhama K. The use of probiotics as ecofriendly alternatives for antibiotics in poultry nutrition. Environ Sci Pollut Res 2018; 25: 10611-10618.

2. Chandramouli $V$, Kailasapathy $K$, Peiris $P$, Jones $M$. An improved method of microencapsulation and its evaluation to protect Lactobacillus spp. in simulated gastric conditions. J Microbiol Methods 2004; 56: 27-35.

3. Se JK, Seung YC, Sae HK, Ok-Ja S, Shik S, Dong SC, Hyun JP. Effect of microencapsulation on viability and other characteristics in Lactobacillus acidophilus ATCC 43121. LWT-Food Sci Technol 2008; 4: 493-500.

4. Annan NT, Borza AD, Truelstrup HL. Encapsulation in alginate-coated gelatin microspheres improves survival of the probiotic Bifidobacterium adolescentis $15703 T$ during exposure to simulated gastro-intestinal conditions. Food Res Int 41: 184-193.

5. Bajracharya $P$, Islam MA, Jiang $T$, Kang SK, Choi YJ, Cho CS. Effect of microencapsulation of Lactobacillus salivarus 29 into alginate/chitosan/alginate microcapsules on viability and cytokine induction. J Microencapsul 2012; 29: 429-436.

6. Lee $K Y$, Heo TR. Survival of Bifidobacterium longum immobilized in calcium alginate beads in simulated gastric juices and bile salt solution. Appl Environ Microbiol 2000; 66: 869-873.

7. Sultana K, Godward G, Reynolds N, Arumugaswamy $R$, Peiris $P$, Kailasapathy $K$. Encapsulation of probiotic bacteria with alginate-starch and evaluation of survival in simulated gastrointestinal conditions and in yoghurt. Int J Food Microbiol 2000; 62: 47-55.

8. Truelstrup HL, Allan WPM, Jin YL, Paulson AT. Survival of Ca-alginate microencapsulated Bifidobacterium spp. in milk and simulated gastrointestinal conditions. Food Microbiol 2002; 19: 35-45.

9. Yaqoob $M U$, Wang $B$, Pei $X$, Xiao $Z$, Wanjing $S$, Jin $Y$, Liu L, Wenjing $T$, Wang $G$, Wang $H$, et al. Microencapsulation of Clostridium tyrobutyricum by spray drying method and its characteristics in-vitro. Pak Vet J 2020; 40(4): 419-424.

10. Mokarram RR, Mortazavi SA, Najafi MBH, Shahidi F. The influence of multi stage alginate coating on survivability of potential probiotic bacteria in simulated gastric and intestinal juice. Food Res Int 2009; 42: 1040-1045.

11. Etchepare MA, Raddatz GC, Flores EMM, Zepka LQ, Jacob-Lopes E, Barin JS, Grosso CRF, Menezes CR. Effect of resistant starch and chitosan on survival of Lactobacillus acidophilus microencapsulated with alginate. LWT-Food Sci Technol 2010; 65: 511-517.

12. Liserre AM, Maria IR, Bernadette DGMF. Microencapsulation of Bifidobacterium animalis subsp. lactis in modified alginate-chitosan beads and evaluation of survival in simulated gastrointestinal conditions. J Food Biotechnol 2007; 21: 1-16.
13. Ding WK, Shah NP. Acid, bile, and heat tolerance of free and microencapsulated probiotic Bacteria. J Food Sci 2007; 72: 446-450.

14. Mandal S, Puniya AK, Singh K. Effect of alginate concentrations on survival of microencapsulated Lactobacillus casei NCDC-298. Int Dairy J 2006; 16: 1190-1195.

15. Iyer C, Kailasapathy K. Effect of co-encapsulation of probiotics with prebiotics on increasing the viability of encapsulated bacteria under in vitro acidic and bile salt conditions and in yogurt. J Food Sci 2005; 70: 18-23.

16. Guerin $D$, Vuillemard JC, Subirade M. Protection of bifidobacteria encapsulated in polysaccharide-protein gel beads against gastric juice and bile. J Food Prot 2003; 66: 2076-2084.

17. Picot A, Lacroix C. Encapsulation of bifidobacteria in whey protein-based microcapsules and survival in simulated gastrointestinal conditions and in yoghurt. Int Dairy J 2004; 14: 505-515.

18. Sun W, Griffiths MW. Survival of bifidobacteria in yoghurt and stimulated gastric juice following immobilization in gellan-xanthan beads. Int J Food Microbiol 2000; 61: 17-25.

19. Le-Tien C, Millette M, Mateescu MA, Lacroix M. Modified alginate and chitosan for lactic acid bacteria immobilization. Biotechnol. Appl Biochem 2004; 39: 347354.

20. Trindade CSF, Grosso CRF. The effect of the immobilization of Lactobacillus acidophilus and Bifidobacterium lactis in alginate on their tolerance to gastrointestinal secretions. Milchwissenschaft 2000; 55 : 496-499.

21. Krasaekoopt W, Bhandari B, Deeth H. Review: evaluation of encapsulation techniques of probiotics for yogurt. Int Dairy 2003; J13: 3-13.

22. Hansen $L T$, Allan-Wojtas $P M$, Jin $Y L$, Paulson AT. Survival of Ca-alginate microencapsulated Bifidobacterium spp. in milk and simulated gastrointestinal conditions. Food Microbiol 2002; 19: 35 45.

23. Khalf M, Dabour N, Kheadr E, Fliss I. Viability of probiotic bacteria in maple sap products under storage and gastrointestinal conditions. Bioresour Technol 2010; 101: 7966-7972.

24. Pirarat $N$, Komkiew $P$, Channarong $R$, Nantarika $C, E i$ LO, Takayuki K, Masashi M. Viability and morphological evaluation of alginate-encapsulated Lactobacillus rhamnosus GG under simulated tilapia gastrointestinal conditions and its effect on growth performance, intestinal morphology and protection against Streptococcus agalactiae. Anim Feed Sci Technol 2015; 207: 93-103.

25. Albertini B, Vitali B, Passerini N. Development of microparticulate systems for intestinal delivery of Lactobacillus acidophilus and Bifidobacterium lactis. Eur J Pharm Sci 2010; 40: 359-366.

26. Fan Z, Xiao YL, Hyun JP, Min Z. Effect of microencapsulation methods on the survival of freeze-

Trop J Pharm Res, September 2021; 20(9): 1789 
dried Bifidobacterium bifidum. J Microencapsul 2013; 30: 511-518.

27. Tang J, Gong G, Su H, Wu F, Herman C. Performance evaluation of a novel method of frost prevention and retardation for air source heat pumps using the orthogonal experiment design method. Appl Energy 2016; 169: 696-708.

28. Feng Z, Niu W, Cheng C, Liao S. Hydropower system operation optimization by discrete differential dynamic programming based on orthogonal experiment design. Energy. 2017; 126: 720-732. 